\title{
The Efficacy of Endoscopic Papillary Balloon Dilation for Patients with Acute Biliary Pancreatitis
}

\author{
Wei-Chih Sun, ${ }^{1}$ Hoi-Hung Chan, ${ }^{1,2,3,4}$ Kwok-Hung Lai, ${ }^{1,2}$ Tzung-Jiun Tsai, ${ }^{1}$ \\ Huey-Shyan Lin, ${ }^{5}$ Kung-Hung Lin, ${ }^{1}$ Kai-Ming Wang, ${ }^{1}$ Sung-Shuo Kao, ${ }^{1,2}$ Po-Hung Chiang, \\ Jin-Shiung Cheng, ${ }^{1,2}$ Ping-I Hsu, ${ }^{1,2}$ Wei-Lun Tsai, ${ }^{1,2}$ Wen-Chi Chen, ${ }^{1,2}$ \\ Yun-Da Li, ${ }^{1}$ and E-Ming Wang ${ }^{1}$ \\ ${ }^{1}$ Division of Gastroenterology, Department of Internal Medicine, Kaohsiung Veterans General Hospital, Kaohsiung 813, Taiwan \\ ${ }^{2}$ School of Medicine, National Yang-Ming University, Taipei 112, Taiwan \\ ${ }^{3}$ Department of Biological Sciences, National Sun Yat-sen University, Kaohsiung 804, Taiwan \\ ${ }^{4}$ College of Pharmacy and Health Care, Tajen University, Pingtung 907, Taiwan \\ ${ }^{5}$ Department of Health-Business Administration, Fooyin University, Kaohsiung 831, Taiwan \\ Correspondence should be addressed to Hoi-Hung Chan; hhchan@vghks.gov.tw
}

Received 31 October 2014; Revised 22 March 2015; Accepted 29 March 2015

Academic Editor: Vikram Kate

Copyright (C) 2015 Wei-Chih Sun et al. This is an open access article distributed under the Creative Commons Attribution License, which permits unrestricted use, distribution, and reproduction in any medium, provided the original work is properly cited.

Background. No study investigated the efficacy and safety of endoscopic papillary balloon dilation (EPBD) for the treatment of acute biliary pancreatitis (ABP). Method. We retrospectively reviewed the effects of EPBD on patients with ABP from February 2003 to December 2012. The general data, findings of image studies, details of the procedure, and outcomes after EPBD were analyzed. Result. Total 183 patients (male/female: 110/73) were enrolled. The mean age was 65.9 years. Among them, 155 patients had mild pancreatitis. The meantime from admission to EPBD was 3.3 days. Cholangiogram revealed filling defects inside the common bile duct (CBD) in 149 patients. The mean dilating balloon size was $10.5 \mathrm{~mm}$ and mean duration of the dilating procedure was 4.3 minutes. Overall, 124 patients had gross stones retrieved from CBD. Four (2.2\%) adverse events and 2 (1.1\%) intraprocedure bleeding incidents but no procedure-related mortality were noted. Bilirubin and amylase levels significantly decreased after EPBD. On average, patients resumed oral intake within 1.4 days. The clinical parameters and outcomes were similar in patients with different severity of pancreatitis. Conclusion. EPBD can be effective and safe for the treatment of ABP, even in patients presenting with severe disease.

\section{Introduction}

Acute biliary pancreatitis (ABP) is a common disease with an annual incidence of 4.9-80.0/100,000 [1]. In the United States and Western Europe, 35-60\% of the patients with acute pancreatitis resulted from biliary stone [2-4]. Although most of the cases with ABP are mild and self-limited, there are 20\% of patients develop severe complications such as necrotizing pancreatitis and/or multiple organ failure with a mortality rate of $13-50 \%$ [2-5]. The pathogenesis of ABP is complex, and the main factor is transient or persistent ampullary obstruction by gallstones [6-9]. Prolonged obstruction will aggravate pancreatic inflammation and contribute to severe pancreatitis [8]. Previous animal and human studies suggested that duration of obstruction over 48 hours may probably result in pancreatic necrosis [10-13]. With regard to this point of view, any measure that can relieve ampullary obstruction as soon as possible is a crucial part in minimizing the subsequent local or systemic complications [14].

Surgical removal of bile duct stones has been first advocated in 1978; however, the associated mortality was unacceptably high and up to $67 \%$ in a randomized trial $[15,16]$. Sphincterotomy (EST) for the treatment of ABP was reported by Safrany et al. in 1980, with regard to its nature of less 
invasiveness than that of surgery [17]. Current guidelines recommend emergency EST in the treatment of patients with ABP with concomitant cholangitis and/or persistent biliary obstruction regardless of the predicted severity of pancreatitis [18-21]. On the other hand, endoscopic papillary balloon dilation (EPBD), which is easy to perform using the wireguided method, has become an alternative to EST for the treatment of CBDS since its first introduction by Staritz et al. in 1982 [22]. Although EPBD is not commonly used in western countries due to the consideration of post-ERCP pancreatitis, it is widely used as EST in Asian countries with good efficacy [23]. Nevertheless, no study assessed the effects of EPBD in patients with ABP. In order to investigate the efficacy and safety of EPBD in the treatment of ABP, we conducted a retrospective study to share the experience in our hospital.

\section{Materials and Methods}

2.1. Patients. Between February 2003 and December 2012, consecutive patients with ABP successfully managed by ERCP/EPBD in Kaohsiung Veterans General Hospital were reviewed. The successful EPBD was defined as a complete performance of balloon dilation and the subsequent stone extraction procedures with clearance of bile duct (no gross stone was found in cholangiography) within two endoscopic sessions. Total 500 patients were diagnosed of acute biliary pancreatitis. Among them, three hundred and seventeen patients who did not receive EPBD were excluded from the study, which include 25 contraindications with/without emergency percutaneous drainage, 30 refusals of ERCP, 96 cases of spontaneous stone pass-out before ERCP, 24 failures of ERCP, 93 cases of diagnostic ERCP only, 48 cases of EST, and one failure of EPBD.

Diagnosis of acute pancreatitis was established when fulfilling any two of the following three criteria: (1) typical abdominal pain (acute onset of a persistent, severe, epigastric pain often radiating to back); (2) serum amylase or lipase levels higher than three times the upper limit of normal; (3) characteristic findings of acute pancreatitis in abdominal ultrasound or contrast-enhanced computed tomography (CECT) $[18,19,24,25]$. A biliary etiology was based on the exclusion of alcoholic or metabolic causes of pancreatitis and the presence of at least one of the following criteria: (1) gallbladder stone or sludge found by ultrasound or CECT; (2) dilated common bile duct (CBD) found by ultrasound or CECT (diameter > $7 \mathrm{~mm}$ if gallbladder is intact and diameter $>11 \mathrm{~mm}$ if gallbladder has been removed); (3) abnormal liver biochemistries including alanine aminotransferase $($ ALT $)>40 \mathrm{U} / \mathrm{L}$, alkaline phosphatase $($ Alk-P) $>128 \mathrm{U} / \mathrm{L}, \gamma$-glutamyltransferase $(\gamma$ GT) $>60 \mathrm{U} / \mathrm{L}$, or an elevated serum bilirubin level $>1.6 \mathrm{mg} /$ dL. Severe pancreatitis was defined as Ranson's score $\geqq 3$ and/or CT severity index $>3[26,27]$. In addition, acute cholangitis was defined by Charcot's triad (fever $>38.5^{\circ} \mathrm{C}$, epigastric pain, and jaundice) or signs of sepsis [14].

Some meta-analyses did not suggest emergency ERCP for mild pancreatitis [28-30], so patients were stratified into group A (mild pancreatitis) and group B (severe pancreatitis) for further comparison of clinical outcomes and to determine which one was beneficial to the endoscopic procedure.
2.2. Timing of Endoscopic Treatment. Currently, all guidelines recommended an emergency ERCP in patients with ABP with coexisting cholangitis and/or persistent biliary obstruction, but the optimal timing for ERCP differed among the guidelines: within 72 hours after onset of symptoms (World Congress of Gastroenterology, American Thoracic Society, British Society of Gastroenterology, Dutch Society of Internal Medicine), within 24 hours after hospital admission (German and American College of Gastroenterology), or controversial (International Association of Pancreatology, American Gastroenterological Association, Japanese Guidelines) [31]. In our study, when patients had either concomitant cholangitis or persistent biliary obstruction with the presentation of Charcot's triad, bacteremia, progressive abdominal pain, or deterioration of liver biochemistries, we tended to perform ERCP as early (within 72 hours after hospital admission) as possible.

2.3. Endoscopic Procedures. Patients were conscious for this procedure and received $10 \%$ xylocaine spray for local anesthesia of the pharynx, intramuscular injection with $40 \mathrm{mg}$ hyoscine- $N$-butylbromide, and intramuscular injection with 25-50 mg meperidine. ERCP was performed in the standard manner using a side-view endoscope (JF-240; Olympus Optical Corporation, Tokyo, Japan). After selective cannulation of the common bile duct by the catheter, cholangiography was performed to evaluate the size of $\mathrm{CBD}$, presence of filling defects inside $\mathrm{CBD}$, and size of $\mathrm{CBD}$ filling defects. A 0.035-inch guide wire (Boston Scientific, Corp, MA, USA) was then inserted into the bile duct through the catheter. A dilating balloon (CRE balloon $5.5 \mathrm{~cm}$ in length, $6-8 \mathrm{~mm} / 8_{-}$ $10 \mathrm{~mm} / 10-12 \mathrm{~mm} / 12-15 \mathrm{~mm}$ in diameter; Boston Scientific, Corp, Ireland) was passed via the prepositioned 0.035 inch guide wire into the bile duct. Using fluoroscopic and endoscopic guidance, the balloon was inflated with sterile saline solution up to the optimal size (at least $>$ six $\mathrm{mm}$ in diameter) and duration (from 1.5 to 5 minutes) according to the patients' condition and tolerance. In order to minimize the risk of perforation, the size of the balloon should be not exceed the size of the CBD. After the balloon and guide wire were removed, the CBDS was retrieved out using a Dormia basket or balloon-tipped catheter with or without the aid of mechanical lithotripsy (BML-4Q; Olympus Optical, Tokyo, Japan). Unnecessary cannulation or contrast injection of pancreatic duct was avoided. A second attempt of stone extraction was performed within three days if there was incomplete removal of stones in the first treatment session. All the patients were observed in the hospital for at least 24 hours after endoscopic treatment.

2.4. Assessments and Outcomes. Demographic data of patients and hospital course was collected from clinical records, including presence of juxtapapillary diverticula (JPD), pancreatic duct enhancement, CBD diameter, number and size of stones, size of dilating balloon, and dilating duration, and presence of extracted stone was recorded. Successful bile duct clearance was defined as complete if the final cholangiogram revealed no more filling defects. The day after the endoscopic 
procedure, a blood sample for measurement of serum amylase and total bilirubin was obtained. ERCP/EPBD related adverse events were recorded according to the definitions and grading systems from the consensus of an American Society of Gastrointestinal Endoscopy Workshop [32]. The definition for exacerbation of pancreatitis after ERCP is as follows: (1) new or worsened abdominal pain, (2) rise of serum amylase at least three times above the upper limit of normal at 24 hours after ERCP, (3) requiring at least 2 days of hospitalization (2-3 days: mild degree; 4-10 days: moderate degree; more than 10 days: severe degree). The definition for post-ERCP cholangitis is (1) fever $>38.5^{\circ} \mathrm{C}$ and (2) persistent cholestasis more than 24 hours. The definition for post-ERCP cholecystitis is (1) newly developed pain and tenderness in RUQ and (2) image of gallbladder wall thickening and pericholecystic fluid. The definition for post-ERCP bleeding is hematemesis and/or melena with a hemoglobin decrease of at least $2 \mathrm{~g} / \mathrm{dL}$ or the need for blood transfusion. Time from admission to ERCP/EPBD, time to resume oral intake after ERCP/EPBD, total hospital days, incidence of ERCP/EPBD related adverse events, and evolutions of laboratory data were assessed to measure the clinical effect and safety of $\mathrm{ERCP} / \mathrm{EPBD}$ on patients with ABP.

2.5. Ethics Statement. This study was approved by the Ethics Committee and the Institutional Review Board of the Kaohsiung Veterans General Hospital (VGHKS13-CT6-12). This is a retrospective study that did not involve patient intervention or the need for obtaining clinical specimens, and all the data were analyzed anonymously. Therefore, informed consent was waived. The waiving of informed consent was approved by the Kaohsiung Veterans General Hospital Institutional Review Board.

2.6. Statistical Analysis. All statistical analyses were performed using the PASW statistics (IBM, New York, NY, USA). The continuous valuables are expressed as mean \pm SD. Pearson Chi-square analysis or Fisher's exact test was used for the comparison of categorical variables, while continuous variables were compared using the paired-sample and independent-sample $t$-tests. Multivariable logistic regression was used to find out the possible predictors for CBD stones. A two-tailed $P$ value of $<0.05$ was considered significant in all tests.

\section{Results}

Within the study period, a total of 183 patients were enrolled in this retrospective study. Characteristics of overall patients were shown in Table 1 . There were $110(60.7 \%)$ males and 73 (39.3\%) females. The mean age of the patients was 65.9 years. $155(84.7 \%)$ patients were diagnosed as mild pancreatitis and the rest of $28(15.3 \%)$ were severe in degree. Radiological examinations revealed the gallbladder in situ in 165 (90.2\%) patients (147 had gallbladder stones) and presence of CBD stones in $91(49.7 \%)$ patients. The results of EPBD and clinical outcomes were shown in Table 2. The meantime from admission to receiving EPBD was 3.3 days. Cholangiogram revealed dilated $\mathrm{CBD}$ in $159(86.9 \%)$ patients with mean $\mathrm{CBD}$ size of $11.8 \pm 4.2 \mathrm{~mm}$. There was positive filling defects inside CBD in $149(81.4 \%)$ patients, and the mean filling defect size was $6.8 \pm 4.6 \mathrm{~mm}$. The mean size of dilating balloon was $10.5 \pm 1.8 \mathrm{~mm}$ and mean duration of the dilating procedure was $4.3 \pm 1.1$ minutes. There were gross stones retrieved from $\mathrm{CBD}$ in $124(67.8 \%)$ patients. The endoscopic treatment was successful in the first session of 179 (97.8\%) patients. Four $(2.2 \%)$ patients had large CBD stones $(>1.5 \mathrm{~cm})(2$ of them received mechanical lithotripsy in first session), whom required second endoscopic treatment to remove residual CBD stones within three days. The rate of positive pancreatic duct injection was $50.8 \%$ of patients, and it was significantly higher in the patients with severe pancreatitis than in those with mild pancreatitis $(67.9 \%$ versus $47.7 \%, P=$ $0.05)$. There were $5(2.7 \%)$ procedure-related adverse events, including 3 mild pancreatitis, 1 cholangitis, and 1 cholecystitis. All the complications could be controlled by conservative treatment and no procedural mortality was noted. EPBD caused the reduction of serum amylase in $90.7 \%$ of patients and reduction of serum total bilirubin in $83.1 \%$ of patients. On average, time to resume oral intake after ERCP was 1.4 days. The average hospital day was 9.1 and 9.6 for patients with mild and severe pancreatitis, respectively.

Patients were divided into two groups: (A) 155 patients with mild pancreatitis and (B) 28 patients with severe pancreatitis. Baseline data of the two groups of patients were shown in Table 1. Significant differences in serum level of WBC, blood sugar, amylase, and borderline significant differences in age and serum total bilirubin level were found between the two groups. There were significant difference in size of dilating balloon and borderline difference in pancreatic duct enhancement (Table 2). Other clinical outcomes were similar between the two groups. The evolution of serum total bilirubin and serum amylase level by EPBD in overall patients and between patients with the mild and severe degree of acute biliary pancreatitis was shown in Table 3. Between the two groups, the levels of serum total bilirubin were significantly different before EPBD but there was no significant difference after EPBD. The levels of serum total bilirubin were significantly decreased in overall patients, regardless of the severity of pancreatitis. Although the levels of serum amylase were significantly decreased after EPBD in overall patients, there were no such similar differences in the reduction of serum amylase between the two groups. Moreover, the levels of serum amylase before and after EPBD were not significantly different between the two groups. Multivariable logistic regression analysis revealed that old age and high serum bilirubin level before ERCP are significant predictors for gross stone retrieved during the ERCP/EPBD procedures (Table 3 ).

\section{Discussion}

Since the introduction of endoscopic treatment of ABP, it has been proved to be beneficial to the outcome of the disease [33]. Although EPBD has been shown to be an alternative to EST to remove the common bile duct stones with a similar success rate and lower risk of immediate complications such as bleeding or perforation [32-38], the clinical effect of EPBD for the treatment of $\mathrm{ABP}$ is rarely reported due to the fact that 
TABLE 1: Characteristics of overall patients and comparisons between patients with mild (A) and severe (B) degree of acute biliary pancreatitis.

\begin{tabular}{|c|c|c|c|c|}
\hline Characteristics & Overall $(n=183)$ & Group A $(n=155)$ & Group B $(n=28)$ & $P$ value \\
\hline Gender (male/female) & $110 / 73$ & $93 / 62$ & $17 / 11$ & 0.94 \\
\hline Age (mean $\pm S D$, years) & $65.9 \pm 17.5$ & $66.9 \pm 17.3$ & $60.3 \pm 17.6$ & 0.06 \\
\hline Body mass index & $24.7 \pm 3.6$ & $24.7 \pm 3.5$ & $24.9 \pm 3.9$ & 0.71 \\
\hline \multicolumn{5}{|l|}{ Symptom } \\
\hline Fever & 44 & 34 & 10 & 0.09 \\
\hline Nausea and vomiting & 111 & 94 & 17 & 0.99 \\
\hline Abdominal pain & 103 & 85 & 18 & 0.35 \\
\hline Jaundice & 145 & 119 & 26 & 0.12 \\
\hline \multicolumn{5}{|l|}{ Laboratory data } \\
\hline WBC $\left(\times 10^{3} \mathrm{cu} \mathrm{mm}^{-1}\right)$ & $11.7 \pm 4.4$ & $11.3 \pm 4.4$ & $13.6 \pm 3.9$ & 0.01 \\
\hline Platelet $\left(\times 10^{3} \mathrm{cu} \mathrm{mm}^{-1}\right)$ & $196 \pm 66$ & $192 \pm 67$ & $217 \pm 58$ & 0.09 \\
\hline INR & $1.04 \pm 0.13$ & $1.06 \pm 0.14$ & $1.04 \pm 0.11$ & 0.37 \\
\hline AST/ALT (IU/L) & $264 \pm 443 / 275 \pm 295$ & $262 \pm 477 / 261 \pm 304$ & $273 \pm 170 / 351 \pm 229$ & $0.84 / 0.14$ \\
\hline Alk-P/ $\gamma$-GT (IU/L) & $200 \pm 142 / 479 \pm 418$ & $200 \pm 145 / 459 \pm 398$ & $200 \pm 126 / 595 \pm 519$ & $0.99 / 0.25$ \\
\hline Total bilirubin $(\mathrm{mg} / \mathrm{dL})$ & $3.7 \pm 2.7$ & $3.8 \pm 2.8$ & $3.2 \pm 1.5$ & 0.09 \\
\hline $\mathrm{LDH}(\mathrm{IU} / \mathrm{L})$ & $311 \pm 177$ & $303 \pm 179$ & $349 \pm 164$ & 0.23 \\
\hline Blood sugar (mg/dL) & $159 \pm 67$ & $154 \pm 62$ & $190 \pm 84$ & 0.04 \\
\hline Amylase (IU/L) & $1351 \pm 1309$ & $1176 \pm 1188$ & $2302 \pm 1539$ & $<0.01$ \\
\hline Lipase (IU/L) & $12310 \pm 13871$ & $11419 \pm 13535$ & $16798 \pm 14918$ & 0.09 \\
\hline \multicolumn{5}{|l|}{ Radiological finding } \\
\hline Gallbladder in situ & 165 & $140(90.3 \%)$ & $25(89.3 \%)$ & 0.54 \\
\hline Gallbladder stone & 147 & 126 & 21 & \\
\hline Dilated CBD & 121 & $104(67.1 \%)$ & $17(60.7 \%)$ & 0.51 \\
\hline CBD stone & 91 & 77 (49.7\%) & $14(50.0 \%)$ & 0.98 \\
\hline
\end{tabular}

SD, standard deviation; WBC, white blood cell; INR, international normalized ratio; AST, aspartate transaminase; ALT, alanine transaminase; Alk-P, alkaline phosphatase; $\gamma$-GT, $\gamma$-glutamyltransferase; LDH, lactic dehydrogenase; CBD, common bile duct.

the side effect of pancreatitis was emphasized before. In fact, in this study, the incidence of overall adverse events was only $2.2 \%$ and all patients recovered after conservative treatment. Regarding the literature, although there is no difference in overall complication rates between EST and EPBD, a higher risk of post-ERCP pancreatitis was reported in some studies $[39,40]$. Certain predictive factors were identified for the development of post-ERCP pancreatitis such as female gender, difficult cannulation, pancreatic duct injection, and normal serum total bilirubin level [41-43]. In this study, most patients (60.7\%) were males and $81.9 \%$ had an elevated serum total bilirubin level. Superfluous injection of contrast medium into the pancreatic duct is certainly considered to lead to increasing the risk of pancreatitis. Although the considerable amount of our patients had encountered pancreatic duct injection, the volume of contrast medium injection was quietly minimized. Once the head portion of pancreatic duct filled with contrast, we would stop injection immediately and withdraw the catheter in order to minimize the parenchymal injury. Moreover, from the latest reports in recent 5 years $[39,44-50]$, pancreatitis more frequently developed in the patients using the small balloon $(8 \mathrm{~mm})$ and short duration $(<3 \mathrm{~min})$ than the patients using the large balloon and long duration. In the report of randomized trial from Liao et al. [51], compared with conventional 1-minute EPBD, 5-minute EPBD improves efficacy of stone extraction and reduces the risk of pancreatitis. A meta-analysis also demonstrated the duration of EPBD is inversely associated with pancreatitis risk [52]. Besides, long EPBD can adequately loosen the intact sphincter; the widely opened papillary orifice may facilitate the insertion of accessory instruments into the bile duct and decrease the injury of the pancreas $[36,53]$. In this study, the mean dilating procedure duration was 4.3 minutes and the mean balloon size was $10.5 \mathrm{~mm}$, and the aforementioned reasons might explain why the incidence of pancreatitis after EPBD was low and only $9.9 \%$ patients had hyperamylasemia.

Biliary decompression theoretically ceases progression of biliary pancreatitis and reduces further complications. However, there is still lack of consensus on the role of endoscopic treatment for $\mathrm{ABP}$ with regard to the predicted severity of pancreatitis [31]. In some meta-analysis and systemic review studies, early ( $\leqq 72$ hours after admission) routine treatment in mild pancreatitis without concomitant cholangitis or biliary obstruction did not affect the disease course and even causes more mortality $[28,54]$. In our study, although most of our patients had mild degree pancreatitis (84.7\%), the clinical outcomes (improvement of pancreatitis and the occurrence of complications) of treatment by EPBD were not significantly different between the two groups. There was a trend that we tended to arrange endoscopic treatment sooner for group B (meantime from admission to ERCP: 2.8 days) than group A (meantime from admission to ERCP: 3.4 days) $(P=0.08)$. 
TABLE 2: Results of EPBD and clinical parameters in overall patients and comparisons between mild (A) and severe (B) degree of acute biliary pancreatitis.

\begin{tabular}{|c|c|c|c|c|}
\hline Results of EPBD & Overall $(n=183)$ & Group A $(n=155)$ & Group B $(n=28)$ & $P$ value \\
\hline Time from admission to initial ERCP (days) & $3.3 \pm 2.4$ & $3.4 \pm 2.5$ & $2.8 \pm 1.5$ & 0.08 \\
\hline Juxtapapillary diverticulum & $55(30.1 \%)$ & $49(31.6 \%)$ & $6(21.4 \%)$ & 0.28 \\
\hline Dilated CBD & $159(86.9 \%)$ & $136(87.7 \%)$ & $23(82.1 \%)$ & 0.42 \\
\hline Mean size of $\mathrm{CBD}(\mathrm{mm})$ & $11.8 \pm 4.2$ & $11.9 \pm 4.0$ & $11.5 \pm 5.0$ & 0.75 \\
\hline Positive filling defects within CBD & $149(81.4 \%)$ & $130(83.9 \%)$ & $19(67.9 \%)$ & 0.23 \\
\hline Mean size of CBD filling defects ( $\mathrm{mm})$ & $6.8 \pm 4.6$ & $6.9 \pm 4.7$ & $6.0 \pm 3.3$ & 0.14 \\
\hline Dilating balloon size ( $\mathrm{mm})$ & $10.5 \pm 1.8$ & $10.6 \pm 1.9$ & $9.9 \pm 1.3$ & 0.04 \\
\hline Dilating procedure duration (min) & $4.3 \pm 1.1$ & $4.3 \pm 1.1$ & $4.3 \pm 1.0$ & 0.95 \\
\hline Gross stone retrieved from CBD & $124(67.8 \%)$ & $108(69.7 \%)$ & $16(57.1 \%)$ & 0.19 \\
\hline Pancreatic duct injection & $93(50.8 \%)$ & $74(47.7 \%)$ & $19(67.9 \%)$ & 0.05 \\
\hline Number of mechanical lithotripsies & $2(1.1 \%)$ & $2(1.3 \%)$ & $0(0.0 \%)$ & 0.72 \\
\hline \multicolumn{5}{|l|}{ Treatment success } \\
\hline First session & $179(97.8 \%)$ & $151(97.4 \%)$ & $28(100 \%)$ & 0.51 \\
\hline Second session & 4 & 4 & 0 & \\
\hline Procedure-related adverse events & $4(2.2 \%)$ & $3(1.9 \%)$ & $1(3.6 \%)$ & 0.49 \\
\hline Exacerbation of pancreatitis & 2 & 1 & 1 & \\
\hline Cholangitis & 1 & 1 & 0 & \\
\hline Cholecystitis & 1 & 1 & 0 & \\
\hline Intraprocedure bleeding & $2(1.1 \%)$ & $2(1.3 \%)$ & $0(0.0 \%)$ & 0.72 \\
\hline \multicolumn{5}{|l|}{ Evolution of laboratory data after EPBD } \\
\hline Amylase: increase/decrease & $17(9 \%) / 166(91 \%)$ & $15(10 \%) / 140(90 \%)$ & $2(7 \%) / 26(93 \%)$ & 0.67 \\
\hline Total bilirubin: increase/decrease & $31(17 \%) / 152(83 \%)$ & $28(18 \%) / 127(82 \%)$ & $3(11 \%) / 25(89 \%)$ & 0.34 \\
\hline Time to resume oral intake after EPBD (days) & $1.4 \pm 0.9$ & $1.4 \pm 0.9$ & $1.5 \pm 0.9$ & 0.87 \\
\hline Total hospital day (days) & $9.2 \pm 4.5$ & $9.1 \pm 4.5$ & $9.6 \pm 4.3$ & 0.63 \\
\hline
\end{tabular}

EPBD, endoscopic papillary balloon dilation; ERCP, endoscopic retrograde cholangiopancreatography; CBD, common bile duct.

TABLE 3: Predictive factors of gross stone retrieved from common bile duct.

\begin{tabular}{|c|c|c|c|c|}
\hline Predicted factor & $\begin{array}{c}\text { Univariate } \\
\text { HR }(95 \% \text { CI })\end{array}$ & $P$ value & $\begin{array}{l}\text { Multivariate } \\
\text { HR }(95 \% \text { CI })\end{array}$ & $P$ value \\
\hline Age (years) & $1.019(1.001-1.037)$ & 0.038 & $1.024(1.00-1.048)$ & $0.049^{*}$ \\
\hline Sex: male & $1.758(0.937-3.297)$ & 0.079 & $1.676(0.777-3.614)$ & 0.188 \\
\hline Body mass index & $1.048(0.951-1.156)$ & 0.343 & $1.047(0.943-1.164)$ & 0.389 \\
\hline Severity of pancreatitis & $0.580(0.255-1.322)$ & 0.195 & $0.910(0.330-2.510)$ & 0.855 \\
\hline CBD stone in CT or ultrasound & $1.034(0.556-1.923)$ & 0.915 & $0.900(0.420-1.929)$ & 0.787 \\
\hline CBD filling defects in cholangiogram & $1.638(0.762-3.522)$ & 0.207 & $1.748(0.678-4.510)$ & 0.248 \\
\hline T.bil before ERCP & $1.248(1.062-1.467)$ & 0.007 & $1.311(1.039-1.655)$ & $0.023^{*}$ \\
\hline Amylase before ERCP & $1.000(1.000-1.000)$ & 0.490 & $1.000(0.999-1.000)$ & 0.253 \\
\hline Concomitant cholangitis & $1.306(0.615-2.772)$ & 0.488 & $1.565(0.574-4.267)$ & 0.382 \\
\hline
\end{tabular}

HR, hazard ratio; CBD, common bile duct; CT, computed tomography; T.bil, total bilirubin; ERCP, endoscopic retrograde cholangiopancreatography.

${ }^{*} P$ value $<0.05$.

There was no significant difference in the rates of procedurerelated adverse events (A: $1.9 \%$ versus $B: 3.6 \%, P=0.49)$ and intraprocedure bleeding (A: $1.3 \%$ versus $\mathrm{B}: 0.0 \%, P=0.72$ ). In fact, evolutions of laboratory data, including serum amylase level, serum bilirubin level, time from EPBD to resume oral intake (subside of abdominal pain), and total hospital day were similar regardless of severity of pancreatitis.

A small gallstone impacted in the common bile duct was recorded in $26 \%$ to $72 \%$ of $\mathrm{ABP}$ patients when receiving operation in the early phase, but less than $10 \%$ of patients received operation $[15,55]$. Spontaneous pass-out of the bile duct stones was reported in $71 \%$ to $88 \%$ of cases within 48 hours after the onset of $\mathrm{ABP}[8,10]$. Our results showed that overall $68.4 \%$ patients had gross stone retrieved from CBD when EPBD was performed with an average of 3.3 days since admission. It is true that MRCP (or even endoscopic ultrasonography and intraductal ultrasonography) can improve the diagnostic accuracy of small bile duct stones and avoid 
unnecessary ERCP in patients with ABP [56-61]. However, these diagnostic tools are time-consuming and not always available in our institution. In this study, all patients were clinically prone to require the ERCP intervention as soon as possible; so, MRCP was not routinely arranged in this situation. Indeed, we might perform unnecessary therapeutic ERCP in some patients whose stone had already passed out spontaneously, but this procedure was believed to be useful in preventing recurrent pancreatitis. Endoscopic sphincteroplasty may reduce a $29 \%$ to $67 \%$ risk of recurrent biliary events even in the patients without gross stone during ERCP in some reports, but it is still controversial whether this invasive procedure should be a routine procedure in those patients or not $[62,63]$. Although high predictive values of biochemical markers for CBD stones such as serum total bilirubin (especially greater than $4 \mathrm{mg} / \mathrm{dL}$ ) and rising liver biochemistries in patients with $\mathrm{ABP}$ have been reported by several studies [6466], multivariate analysis in our study revealed that old age and high serum bilirubin level at the day before EPBD can be helpful in predicting gross stones retrieved from CBD.

There are some limitations of this study associated with retrospective research which include unequal numbers between patients with mild and severe pancreatitis and lack of well-defined optimal timing for EPBD after admission. Further randomized prospective studies may be needed to support the true efficacy of EPBD and figure out who is the best candidate and when is the best timing to receive EPBD for treatment of acute biliary pancreatitis.

\section{Conclusion}

Endoscopic papillary balloon dilation is effective and safe for the treatment of acute biliary pancreatitis, even in the patients presenting with severe disease.

\section{Conflict of Interests}

The authors have indicated that they have no conflict of interests with regard to the content of this paper.

\section{References}

[1] K. J. van Erpecum, "Complications of bile-duct stones: acute cholangitis and pancreatitis," Best Practice and Research: Clinical Gastroenterology, vol. 20, no. 6, pp. 1139-1152, 2006.

[2] C. F. Frey, H. Zhou, D. J. Harvey, and R. H. White, "The incidence and case-fatality rates of acute biliary, alcoholic, and idiopathic pancreatitis in California, 1994-2001," Pancreas, vol. 33, no. 4, pp. 336-344, 2006.

[3] K. Mergener and J. Baillie, "Endoscopic treatment for acute biliary pancreatitis: when and in whom?" Gastroenterology Clinics of North America, vol. 28, no. 3, pp. 601-613, 1999.

[4] S. K. C. Toh, S. Phillips, and C. D. Johnson, "A prospective audit against national standards of the presentation and management of acute pancreatitis in the South of England," Gut, vol. 46, no. 2, pp. 239-243, 2000.

[5] S.-T. Fan, E. C. S. Lai, F. P. T. Mok, C.-M. Lo, S.-S. Zheng, and J. Wong, "Early treatment of acute biliary pancreatitis by endoscopic papillotomy," The New England Journal of Medicine, vol. 328, no. 4, pp. 228-232, 1993.

[6] J.-L. Frossard, M. L. Steer, and C. M. Pastor, "Acute pancreatitis," The Lancet, vol. 371, no. 9607, pp. 143-152, 2008.

[7] E. L. Opie and J. C. Meakins, "Data concerning the etiology and pathology of hemorrhagic necrosis of the pancreas (acute hemorrhagic pancreatitis)," The Journal of Experimental Medicine, vol. 11, no. 4, pp. 561-578, 1909.

[8] J. M. Acosta, C. A. Pellegrini, and D. B. Skinner, "Etiology and pathogenesis of acute biliary pancreatitis," Surgery, vol. 88, no. 1, pp. 118-125, 1980.

[9] J. P. Neoptolemos, “The theory of 'persisting' common bile duct stones in severe gallstone pancreatitis," Annals of the Royal College of Surgeons of England, vol. 71, no. 5, pp. 326-331, 1989.

[10] J. M. Acosta, O. M. R. Galli, R. Rossi, A. V. Chinellato, and C. A. Pellegrini, "Effect of duration of ampullary gallstone obstruction on severity of lesions of acute pancreatitis," Journal of the American College of Surgeons, vol. 184, no. 5, pp. 499-505, 1997.

[11] T. Hirano and T. Manabe, "A possible mechanism for gallstone pancreatitis: repeated short-term pancreaticobiliary duct obstruction with exocrine stimulation in rats," Proceedings of the Society for Experimental Biology and Medicine, vol. 202, no. 2, pp. 246-252, 1993.

[12] M. Rünzi, A. Saluja, M. M. Lerch, R. Dawra, H. Nishino, and M. L. Steer, "Early ductal decompression prevents the progression of biliary pancreatitis: an experimental study in the opossum," Gastroenterology, vol. 105, no. 1, pp. 157-164, 1993.

[13] N. Senninger, F. G. Moody, J. C. U. Coelho, and D. H. van Buren, "The role of biliary obstruction in the pathogenesis of acute pancreatitis in the opossum," Surgery, vol. 99, no. 6, pp. 688693, 1986.

[14] A. Oría, D. Cimmino, C. Ocampo et al., "Early endoscopic intervention versus early conservative management in patients with acute gallstone pancreatitis and biliopancreatic obstruction: a randomized clinical trial," Annals of Surgery, vol. 245, no. 1, pp. 10-17, 2007.

[15] J. M. Acosta, R. Rossi, and O. M. Rubio Galli, "Early surgery for acute gallstone pancreatitis: evaluation of a systematic approach," Surgery, vol. 83, no. 4, pp. 367-370, 1978.

[16] T. R. Kelly and D. S. Wagner, "Gallstone pancreatitis: a prospective randomized trial of the timing of surgery," Surgery, vol. 104, no. 4, pp. 600-605, 1988.

[17] L. Safrany, B. Neuhaus, S. Krause, G. Portocarrero, and B. Schott, "Endoskopische Papillotomie bei akuter, biliär bedingter Pankreatitis," Deutsche Medizinische Wochenschrift, vol. 105, no. 4, pp. 115-119, 1980.

[18] P. A. Banks, M. L. Freeman, R. Fass et al., "Practice guidelines in acute pancreatitis," The American Journal of Gastroenterology, vol. 101, no. 10, pp. 2379-2400, 2006.

[19] UK Working Party on Acute Pancreatitis, "UK guidelines for the management of acute pancreatitis," Gut, vol. 54, supplement 3, pp. iiil-iii9, 2005.

[20] R. Pezzilli, A. Zerbi, V. di Carlo, C. Bassi, and G. F. delle Fave, "Practical guidelines for acute pancreatitis," Pancreatology, vol. 10, no. 5, pp. 523-535, 2010.

[21] T. Takada, "JPN guidelines 2010. Foreword," Journal of HepatoBiliary-Pancreatic Sciences, vol. 17, no. 1, pp. 1-2, 2010.

[22] M. Staritz, K. Ewe, and K. H. M. Z. Büschenfelde, "Endoscopic papillary dilatation, a possible alternative to endoscopic papillotomy," The Lancet, vol. 1, no. 8284, pp. 1306-1307, 1982. 
[23] K. H. Lai, H. H. Chan, T. J. Tsai, J. S. Cheng, and P. I. Hsu, "Reappraisal of endoscopic papillary balloon dilation for the management of common bile duct stones," World Journal of Gastrointestinal Endoscopy, vol. 7, no. 2, pp. 77-86, 2015.

[24] T. L. Bollen, H. C. van Santvoort, M. G. H. Besselink, W. H. van Es, H. G. Gooszen, and M. S. van Leeuwen, "Update on acute pancreatitis: ultrasound, computed tomography, and magnetic resonance imaging features," Seminars in Ultrasound, CT and MRI, vol. 28, no. 5, pp. 371-383, 2007.

[25] M. Arvanitakis, M. Delhaye, V. De Maertelaere et al., "Computed tomography and magnetic resonance imaging in the assessment of acute pancreatitis," Gastroenterology, vol. 126, no. 3, pp. 715-723, 2004.

[26] J. H. C. Ranson, "Etiological and prognostic factors in human acute pancreatitis: a review," The American Journal of Gastroenterology, vol. 77, no. 9, pp. 633-638, 1982.

[27] E. J. Balthazar, D. L. Robinson, A. J. Megibow, and J. H. C. Ranson, "Acute pancreatitis: value of CT in establishing prognosis," Radiology, vol. 174, no. 2, pp. 331-336, 1990.

[28] M. C. Uy, M. L. O. Daez, P. P. Sy, V. P. Banez, W. Z. Espinosa, and M. C. Talingdan-Te, "Early ERCP in acute gallstone pancreatitis without cholangitis: a meta-analysis," Journal of the Pancreas, vol. 10, no. 3, pp. 299-305, 2009.

[29] A. Moretti, C. Papi, A. Aratari et al., "Is early endoscopic retrograde cholangiopancreatography useful in the management of acute biliary pancreatitis? A meta-analysis of randomized controlled trials," Digestive and Liver Disease, vol. 40, no. 5, pp. 379-385, 2008.

[30] M. S. Petrov, A. F. Uchugina, and M. V. Kukosh, "Does endoscopic retrograde cholangiopancreatography reduce the risk of local pancreatic complications in acute pancreatitis? A systematic review and metaanalysis," Surgical Endoscopy, vol. 22, no. 11, pp. 2338-2343, 2008.

[31] E.-J. M. van Geenen, H. C. van Santvoort, M. G. H. Besselink et al., "Lack of consensus on the role of endoscopic retrograde cholangiography in acute biliary pancreatitis in published metaanalyses and guidelines: A systematic review," Pancreas, vol. 42, no. 5, pp. 774-780, 2013.

[32] P. B. Cotton, G. M. Eisen, L. Aabakken et al., "A lexicon for endoscopic adverse events: report of an ASGE workshop," Gastrointestinal Endoscopy, vol. 71, no. 3, pp. 446-454, 2010.

[33] J. P. Neoptolemos, N. J. London, D. James, D. L. Carr-Locke, I. A. Bailey, and D. P. Fossard, "Controlled trial of urgent endoscopic retrograde cholangiopancreatography and endoscopic sphincterotomy versus conservative treatment for acute pancreatitis due to gallstones," The Lancet, vol. 2, no. 8618, pp. 979-983, 1988.

[34] N. Fujita, H. Maguchi, Y. Komatsu et al., "Endoscopic sphincterotomy and endoscopic papillary balloon dilatation for bile duct stones: a prospective randomized controlled multicenter trial," Gastrointestinal Endoscopy, vol. 57, no. 2, pp. 151-155, 2003.

[35] J. J. G. H. M. Bergman, E. A. J. Rauws, P. Fockens et al., "Randomised trial of endoscopic balloon dilation versus endoscopic sphincterotomy for removal of bileduct stones," The Lancet, vol. 349, no. 9059, pp. 1124-1129, 1997.

[36] C.-K. Lin, K.-H. Lai, H.-H. Chan et al., "Endoscopic balloon dilatation is a safe method in the management of common bile duct stones," Digestive and Liver Disease, vol. 36, no. 1, pp. 68-72, 2004.

[37] A. Y. B. Teoh, F. K. Y. Cheung, B. Hu et al., "Randomized trial of endoscopic sphincterotomy with balloon dilation versus endoscopic sphincterotomy alone for removal of bile duct stones," Gastroenterology, vol. 144, no. 2, pp. 341.e1-345.e1, 2013.
[38] W.-C. Liao, S.-P. Huang, M.-S. Wu, J.-T. Lin, and H.-P. Wang, "Comparison of endoscopic papillary balloon dilatation and sphincterotomy for lithotripsy in difficult sphincterotomy," Journal of Clinical Gastroenterology, vol. 42, no. 3, pp. 295-299, 2008.

[39] T. H. Baron and G. C. Harewood, "Endoscopic balloon dilation of the biliary sphincter compared to endoscopic biliary sphincterotomy for removal of common bile duct stones during ERCP: a metaanalysis of randomized, controlled trials," The American Journal of Gastroenterology, vol. 99, no. 8, pp. 1455-1460, 2004.

[40] J. A. Disario, M. L. Freeman, D. J. Bjorkman et al., "Endoscopic balloon dilation compared with sphincterotomy for extraction of bile duct stones," Gastroenterology, vol. 127, no. 5, pp. 12911299, 2004.

[41] P. B. Cotton, G. Lehman, J. Vennes et al., "Endoscopic sphincterotomy complications and their management: an attempt at consensus," Gastrointestinal Endoscopy, vol. 37, no. 3, pp. 383393, 1991.

[42] M. L. Freeman, J. A. DiSario, D. B. Nelson et al., "Risk factors for post-ERCP pancreatitis: a prospective, multicenter study," Gastrointestinal Endoscopy, vol. 54, no. 4, pp. 425-434, 2001.

[43] S. Friedland, R. M. Soetikno, J. Vandervoort, H. Montes, T. Tham, and D. L. Carr-Locke, "Bedside scoring system to predict the risk of developing pancreatitis following ERCP," Endoscopy, vol. 34, no. 6, pp. 483-488, 2002.

[44] P.-P. Jin, J.-F. Cheng, D. Liu, M. Mei, Z.-Q. Xu, and L.-M. Sun, "Endoscopic papillary large balloon dilation vs endoscopic sphincterotomy for retrieval of common bile duct stones: a meta-analysis," World Journal of Gastroenterology, vol. 20, no. 18, pp. 5548-5556, 2014.

[45] Y. Feng, H. Zhu, X. Chen et al., "Comparison of endoscopic papillary large balloon dilation and endoscopic sphincterotomy for retrieval of choledocholithiasis: a meta-analysis of randomized controlled trials," Journal of Gastroenterology, vol. 47, no. 6, pp. 655-663, 2012.

[46] G. Stefanidis, C. Christodoulou, S. Manolakopoulos, and R. Chuttani, "Endoscopic extraction of large common bile duct stones: a review article," World Journal of Gastrointestinal Endoscopy, vol. 4, no. 5, pp. 167-179, 2012.

[47] H. H. Chan, K. H. Lai, C. K. Lin et al., "Endoscopic papillary large balloon dilation alone without sphincterotomy for the treatment of large common bile duct stones," BMC Gastroenterology, vol. 11, article 69, 2011.

[48] Y. Liu, P. Su, Y. Lin et al., "Endoscopic sphincterotomy plus balloon dilation versus endoscopic sphincterotomy for choledocholithiasis: a meta-analysis," Journal of Gastroenterology and Hepatology, vol. 28, no. 6, pp. 937-945, 2013.

[49] D. K. Lee and J. W. Han, "Endoscopic papillary large balloon dilation: guidelines for pursuing zero mortality," Clinical Endoscopy, vol. 45, no. 3, pp. 299-304, 2012.

[50] H. Kogure, T. Tsujino, H. Isayama et al., "Short- and long-term outcomes of endoscopic papillary large balloon dilation with or without sphincterotomy for removal of large bile duct stones," Scandinavian Journal of Gastroenterology, vol. 49, no. 1, pp. 121128, 2014.

[51] W.-C. Liao, C.-T. Lee, C.-Y. Chang et al., "Randomized trial of 1-minute versus 5-minute endoscopic balloon dilation for extraction of bile duct stones," Gastrointestinal Endoscopy, vol. 72, no. 6, pp. 1154-1162, 2010.

[52] W.-C. Liao, Y.-K. Tu, M.-S. Wu et al., "Balloon dilation with adequate duration is safer than sphincterotomy for extracting 
bile duct stones: a systematic review and meta-analyses," Clinical Gastroenterology and Hepatology, vol. 10, no. 10, pp. 11011109, 2012.

[53] T. Tsujino, H. Isayana, Y. Komatsu et al., "Risk factors for pancreatitis in patients with common bile duct stones managed by endoscopic papillary balloon dilation," The American Journal of Gastroenterology, vol. 100, no. 1, pp. 38-42, 2005.

[54] F. Tse and Y. Yuan, "Early routine endoscopic retrograde cholangiopancreatography strategy versus early conservative management strategy in acute gallstone pancreatitis," Cochrane Database of Systematic Reviews, vol. 5, Article ID CD009779, 2012.

[55] T. R. Kelly, "Gallstone pancreatitis: pathophysiology," Surgery, vol. 80, no. 4, pp. 488-492, 1976.

[56] J. Romagnuolo, M. Bardou, E. Rahme, L. Joseph, C. Reinhold, and A. N. Barkun, "Magnetic resonance cholangiopancreatography: a meta-analysis of test performance in suspected biliary disease," Annals of Internal Medicine, vol. 139, no. 7, pp. 547-557, 2003.

[57] D. Verma, A. Kapadia, G. M. Eisen, and D. G. Adler, "EUS vs MRCP for detection of choledocholithiasis," Gastrointestinal Endoscopy, vol. 64, no. 2, pp. 248-254, 2006.

[58] F. Tse, L. Liu, A. N. Barkun, D. Armstrong, and P. Moayyedi, "EUS: a meta-analysis of test performance in suspected choledocholithiasis," Gastrointestinal Endoscopy, vol. 67, no. 2, pp. 235-244, 2008.

[59] D. Garrow, S. Miller, D. Sinha et al., "Endoscopic ultrasound: a meta-analysis of test performance in suspected biliary obstruction," Clinical Gastroenterology and Hepatology, vol. 5, no. 5, pp. 616.e1-623.e1, 2007.

[60] S. Kondo, H. Isayama, M. Akahane et al., "Detection of common bile duct stones: comparison between endoscopic ultrasonography, magnetic resonance cholangiography, and helicalcomputed- tomographic cholangiography," European Journal of Radiology, vol. 54, no. 2, pp. 271-275, 2005.

[61] C. Aubé, B. Delorme, T. Yzet et al., "MR cholangiopancreatography versus endoscopic sonography in suspected common bile duct lithiasis: a prospective, comparative study," The American Journal of Roentgenology, vol. 184, no. 1, pp. 55-62, 2005.

[62] T. P. Kinney, R. Lai, and M. L. Freeman, "Endoscopic approach to acute pancreatitis," Reviews in Gastroenterological Disorders, vol. 6, no. 3, pp. 119-135, 2006.

[63] J. T. Frakes, "Biliary pancreatitis: a review. Emphasizing appropriate endoscopic intervention," Journal of Clinical Gastroenterology, vol. 28, no. 2, pp. 97-109, 1999.

[64] L. Chang, S. K. Lo, B. E. Stabile, R. J. Lewis, and C. de Virgilio, "Gallstone pancreatitis: a prospective study on the incidence of cholangitis and clinical predictors of retained common bile duct stones," The American Journal of Gastroenterology, vol. 93, no. 4, pp. 527-531, 1998.

[65] M. E. Cohen, L. Slezak, C. K. Wells, D. K. Andersen, and M. Topazian, "Prediction of bile duct stones and complications in gallstone pancreatitis using early laboratory trends," The American Journal of Gastroenterology, vol. 96, no. 12, pp. 33053311, 2001.

[66] T. Chan, A. Yaghoubian, D. Rosing et al., "Total bilirubin is a useful predictor of persisting common bile duct stone in gallstone pancreatitis," American Surgeon, vol. 74, no. 10, pp. 977980, 2008. 


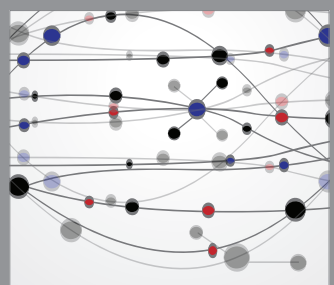

The Scientific World Journal
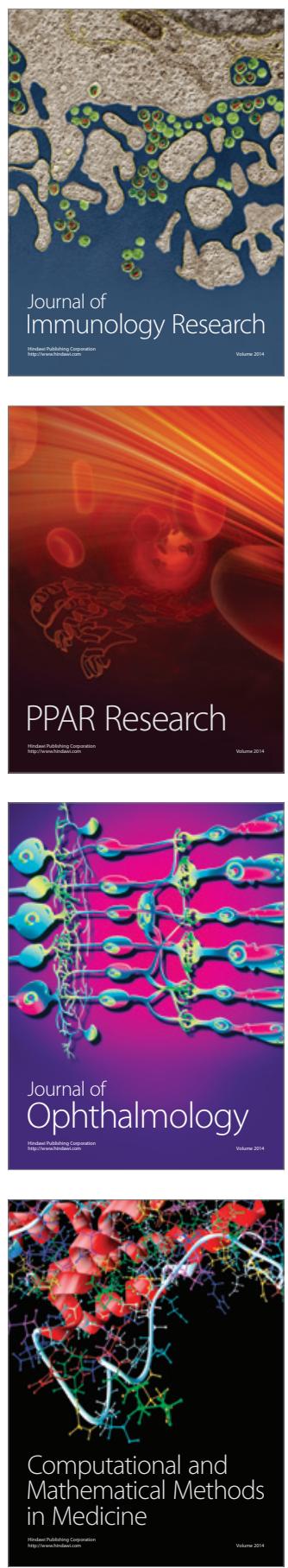

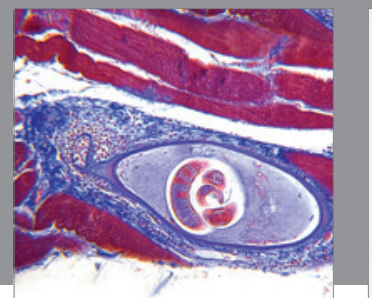

Gastroenterology

Research and Practice
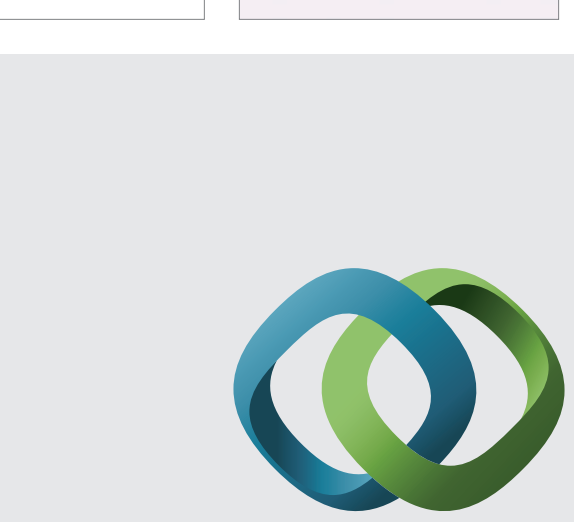

\section{Hindawi}

Submit your manuscripts at

http://www.hindawi.com
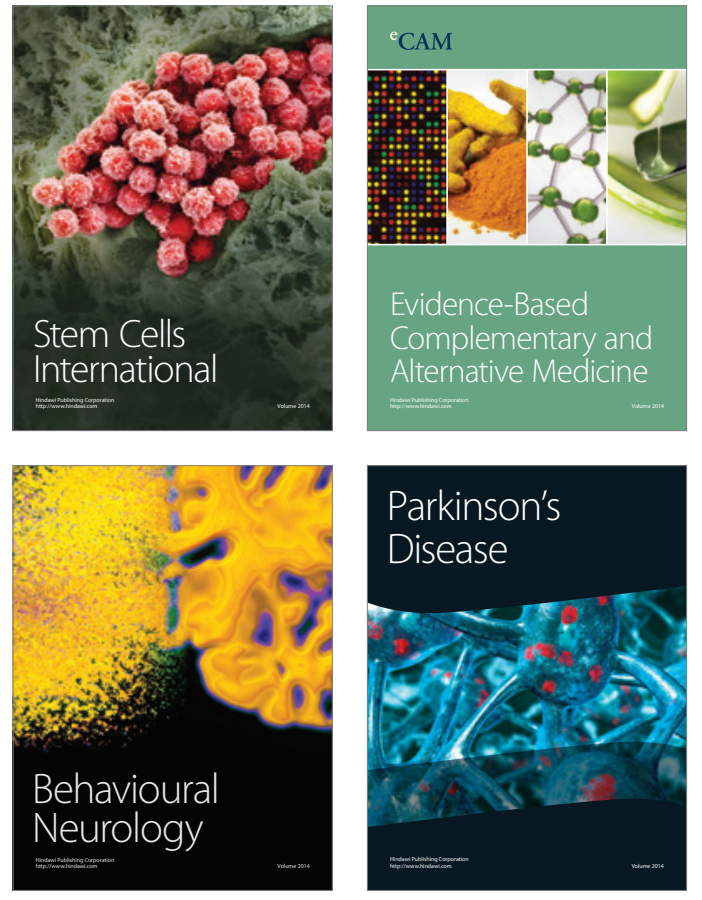
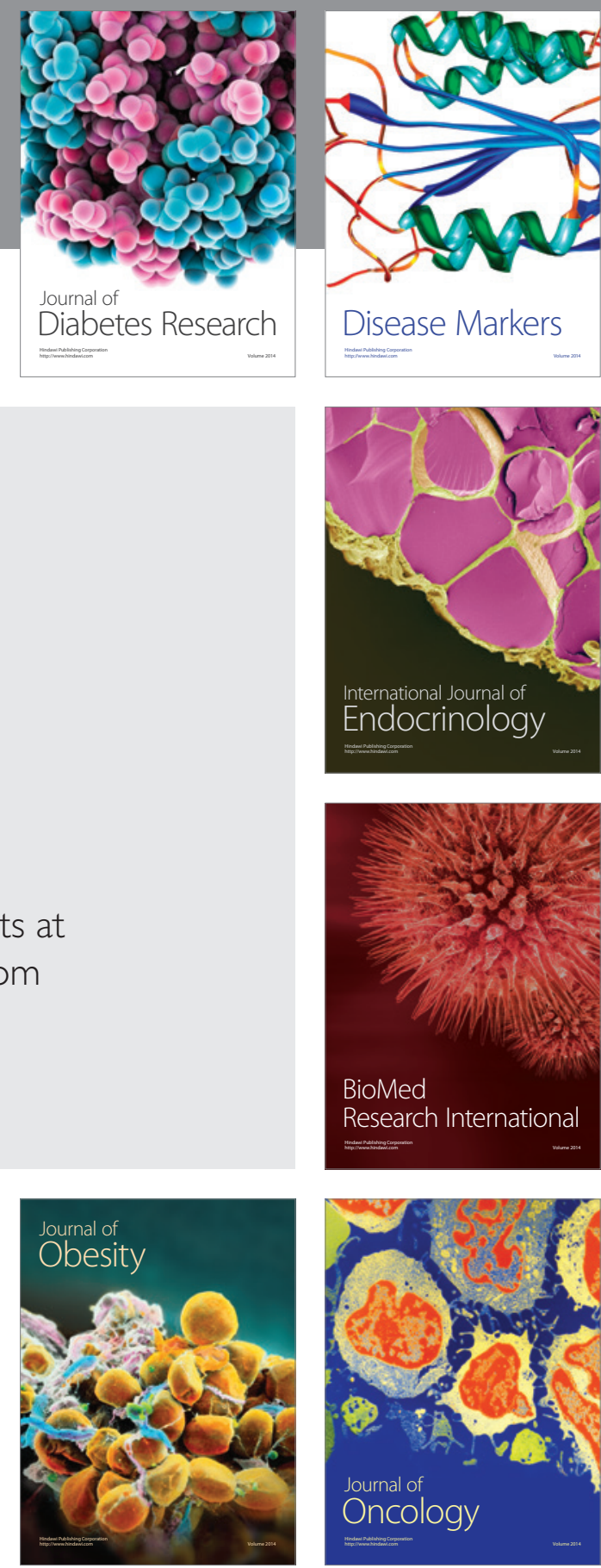

Disease Markers
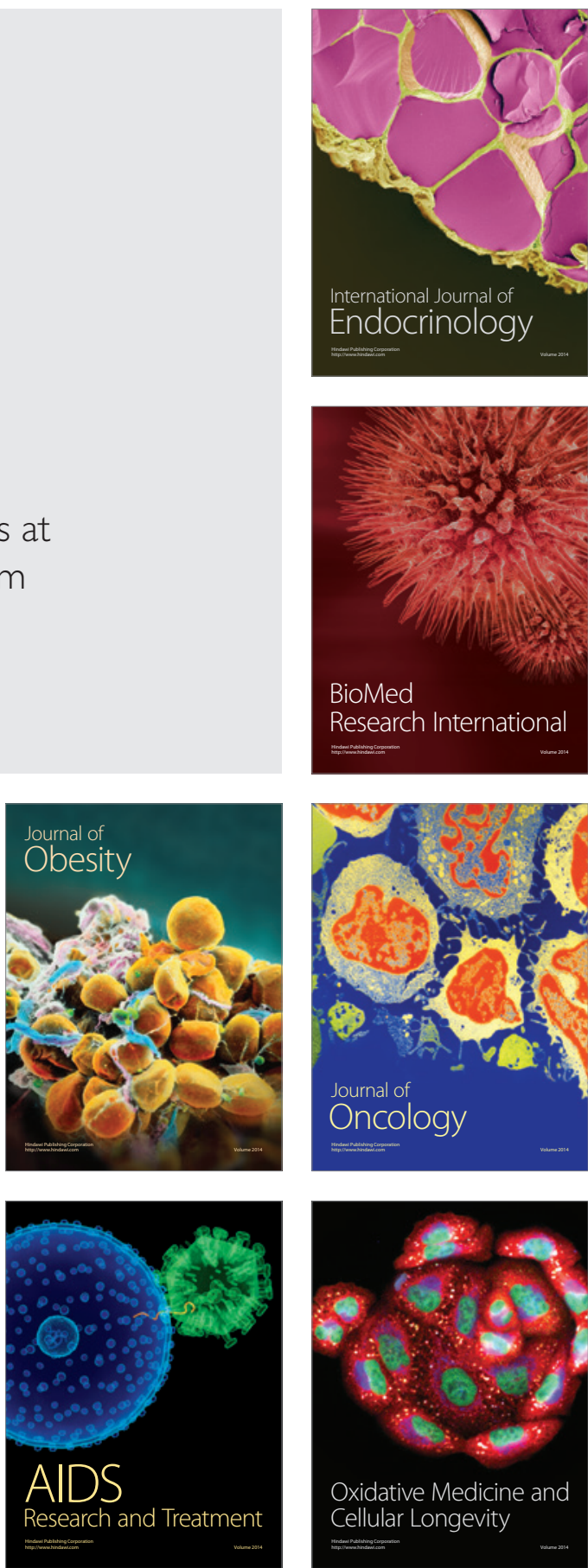